\title{
Glucose metabolic disorder in Klinefelter syndrome: a retrospective analysis in a single Chinese hospital and literature review
}

Shixuan Liu', Tao Yuan ${ }^{1,2^{*}}$, Shuoning Song ${ }^{1}$, Shi Chen ${ }^{1}$, Linjie Wang ${ }^{1}$, Yong Fu', Yingyue Dong ${ }^{1}$, Yan Tang ${ }^{2}$ and Weigang Zhao ${ }^{1,2^{*}+}$

\begin{abstract}
Background: We aimed to investigate the clinical characteristics and islet $\beta$-cell function in patients with Klinefelter syndrome (KS) and hyperglycemia.

Methods: This is a retrospective study. In total, 22 patients diagnosed with KS were identified from the electronic medical record system, including 9 patients with hyperglycemia (total patients with hyperglycemia, THG-KS group) and 5 hyperglycemic KS patients with oral glucose tolerance test (OGTT) results (HG-KS group). An additional 5 subjects with hyperglycemia and 5 normal glucose tolerance (NGT) subjects matched based on body mass index were included as the HG group and NGT group, respectively. Data from clinical and laboratory examinations were collected. We further performed a literature review of KS and hyperglycemia.

Results: We found that KS patients developed abnormal glucose metabolism earlier in life than those without KS, and the median age was 17 years, ranging from 10 years to 19 years. Six of 17 (35.3\%) patients were diagnosed with diabetes mellitus and 3 of 17 (17.6\%) patients were diagnosed with prediabetes. Among 10 patients with both fasting blood glucose and insulin results recorded, there were 8 out of 17 (47.1\%) KS patients had insulin resistance. The prevalence of hypertension and dyslipidemia was higher in patients with hyperglycemia and KS than in patients with NGT KS. Compared with the HG group, insulin sensitivity levels were lower in HG-KS group, whereas homeostasis model assessment of $\beta$-cell function levels $(p=0.047)$ were significantly, indicating higher insulin secretion levels in the HG-KS group.

Conclusions: KS patients develop hyperglycemia earlier in life than those without KS and show lower insulin sensitivity and higher insulin secretion. These patients also have a higher prevalence of other metabolic diseases and may have different frequencies of developing KS-related symptoms.
\end{abstract}

Keywords: Klinefelter syndrome, Diabetes mellitus, Hyperglycemia, Insulin resistance, Hypoglycemic therapy

\footnotetext{
*Correspondence: t75y@sina.com; xiehezhaoweigang@163.com

${ }^{\dagger}$ Tao Yuan and Weigang Zhao contributed equally to this work.

'Department of Endocrinology, Key Laboratory of Endocrinology of National Health Commission, Peking Union Medical College Hospital, Peking Union

Medical College \& Chinese Academy of Medical Sciences, No. 1 Shuaifuyuan Street, Dongcheng District, Beijing0086 100730China

Full list of author information is available at the end of the article
}

(C) The Author(s). 2021 Open Access This article is licensed under a Creative Commons Attribution 4.0 International License, which permits use, sharing, adaptation, distribution and reproduction in any medium or format, as long as you give appropriate credit to the original author(s) and the source, provide a link to the Creative Commons licence, and indicate if changes were made. The images or other third party material in this article are included in the article's Creative Commons licence, unless indicated otherwise in a credit line to the material. If material is not included in the article's Creative Commons licence and your intended use is not permitted by statutory regulation or exceeds the permitted use, you will need to obtain permission directly from the copyright holder. To view a copy of this licence, visit http://creativecommons.org/licenses/by/4.0/ The Creative Commons Public Domain Dedication waiver (http://creativecommons.org/publicdomain/zero/1.0/) applies to the data made available in this article, unless otherwise stated in a credit line to the data. 


\section{Background}

Klinefelter syndrome (KS) is the most frequent sex chromosome disorder of the male population [1], and the estimated prevalence of KS ranges from 1 in 500 to 1 in 1000 in males [2]. KS is characterized by hypergonadotropic hypogonadism with decreased levels of androgens and inhibin $\mathrm{B}$, which cause increased secretion of follicle stimulating hormone (FSH) and luteinizing hormone (LH) through a negative feedback loop [3] and other classical phenotypes, including aspermatogenesis [4], tall and slender bodies with narrow shoulders, long arms and legs, small testes and sparse body hair [5]. The genetic background of KS involves the presence of one or more extra $\mathrm{X}$ chromosomes, and the most universal karyotype is $47 \mathrm{XXY}$, accounting for approximately 80$90 \%$ of patients [1]. Other karyotypes, including 47 XXY/46 XY chimaeras, 48 XXXY, 48 XXYY or 49 $\mathrm{XXXXY}$, have also been detected in the remaining $\mathrm{KS}$ patients [6].

Previous studies have observed that $\mathrm{KS}$ is associated with the development of diabetes mellitus (DM), insulin resistance, hyperinsulinemia, hyperlipidemia, obesity and other metabolic diseases [7]. The prevalence of overt $\mathrm{DM}$ in $\mathrm{KS}$ is estimated to be greater than $10 \%$ depending on the population [8], and abnormal oral glucose tolerance test (OGTT) results are detected in approximately greater than one-third of KS patients [9]. These subjects are characterized by an earlier onset age and a lower body mass index (BMI) than the general population [10]. Epidemiological studies have found that the morbidity and mortality of DM in KS are greater than threefold increased [11, 12]. However, most previous studies focused on either the prevalence of DM or metabolic syndrome among KS patients or different features between KS patients with and without DM, and only a few studies have studied the characteristics of islet $\beta$-cell function between hyperglycemic patients with and without KS.

In this study, we retrospectively summarized the characteristics of patients with hyperglycemia and KS from a single Chinese hospital database, compared clinical features, insulin sensitivity and islet $\beta$-cell secretion function between hyperglycemic subjects with and without $\mathrm{KS}$, and further performed a literature review. We aimed to describe the clinical features and characteristics of islet $\beta$-cell function in patients with $\mathrm{KS}$ and hyperglycemia and to help select the appropriate hypoglycemic therapy for DM patients with KS.

\section{Materials and methods}

\section{Subjects}

This was a retrospective study. The electronic medical record system of Peking Union Medical College Hospital (PUMCH) was used to identify patients with a final diagnosis of KS from January 2000 to December 2019 by searching the clinical notes. KS was diagnosed according to the definite diagnosis of $\mathrm{KS}$ in other hospitals or karyotyping records, and $22 \mathrm{KS}$ patients were identified. After excluding 5 patients without electronic records of laboratory tests, $8 \mathrm{KS}$ patients had normal glucose tolerance (NGT-KS group, $n=8$ ), and $9 \mathrm{KS}$ patients had hyperglycemia (total patients with hyperglycemia, THG$\mathrm{KS}$ group, $n=9$ ). Among these 9 patients, 4 patients diagnosed with DM but without records of OGTT were excluded, and the remaining 5 patients, including $2 \mathrm{DM}$ patients and 3 prediabetes patients, were enrolled in the KS and hyperglycemia group (HG-KS group, $n=5$ ). All patients did not start testosterone treatment at the time of collecting the clinical data. An additional 10 subjects, including 5 subjects with hyperglycemia but without KS (HG group, $n=5$ ) and 5 NGT subjects (NGT group, $n=$ 5 ), were matched with patients in the HG-KS group based on BMI.

The diagnosis of DM was based on the diagnostic criteria of the American Diabetes Association [13]. Prediabetes was defined as fasting blood glucose (FBG) between $6.1 \mathrm{mmol} / \mathrm{L}$ and $6.9 \mathrm{mmol} / \mathrm{L}$ or glycosylated hemoglobin A1c (HbA1c) from 5.7 to $6.4 \%$ or 2 -h postprandial blood glucose (PBG) during 2-h OGTT between $7.8 \mathrm{mmol} / \mathrm{L}$ and $11.1 \mathrm{mmol} / \mathrm{L}$ and no diagnosis of DM. Hyperglycemia included the states of DM and prediabetes. Obesity was defined as BMI $\geq 28 \mathrm{~kg} / \mathrm{m}^{2}$ according to diagnostic criteria for the Asian population [14]. Hypertension was diagnosed based on the following criteria: systolic blood pressure (SBP) $\geq 130 \mathrm{mmHg}$, diastolic blood pressure (DBP) $\geq 85 \mathrm{mmHg}$, or the use of antihypertensive medications. Dyslipidemia was diagnosed based on the following criteria: elevated serum triglyceride (TG) (> $1.7 \mathrm{mmol} / \mathrm{L})$, low serum high density lipoprotein cholesterol level (HDL-c) $(<1.04 \mathrm{mmol} / \mathrm{L})$, or the use of lipid-lowering agents [15].

This study was approved by the PUMCH Ethics Committee and followed the ethical standards of the responsible committee on human experimentation (institution and national) and the Helsinki Declaration of 1964, as revised in 2013. All participants provided written consent for the inclusion of materials pertaining to themselves and acknowledged that they could not be identified via the paper. The participants were fully anonymized.

\section{Clinical data and oral glucose tolerance test}

Clinical history, physical examination and laboratory examination results were collected from the medical database during the period of admission. BMI was calculated as weight $(\mathrm{kg})$ divided by the square of the height in meters $\left(\mathrm{m}^{2}\right)$. Blood pressure was measured thrice after 5 min of rest and was recorded as the mean value of three measurements. 
Blood samples were collected at baseline $(0 \mathrm{~min})$, as well as $30 \mathrm{~min}, 60 \mathrm{~min}, 120 \mathrm{~min}$ and $180 \mathrm{~min}$ after $75-\mathrm{g}$ anhydrous glucose load by oral administration after fasting for 8 to $12 \mathrm{~h}$. Blood samples were used for serum glucose, insulin and $\mathrm{C}$-peptide assays. The quantitative insulin sensitivity check index (QUICKI) [16], insulin sensitivity index proposed by Matsuda et al. (ISImatsuda) [17], the reciprocal of the product of fasting serum insulin and blood glucose referred to as the insulin action index (IAI), the ratio of the area under the curve of glucose and insulin $\left(\mathrm{AUC}_{\mathrm{Glu}} / \mathrm{AUC}_{\mathrm{Ins}}\right)$ [18] and homeostasis model assessment of insulin resistance (HOMAIR) [19] were calculated to reflect insulin resistance. In addition, homeostasis model assessment of $\beta$-cell function (HOMA- $\beta$ ) values [19] and area under the curve values for insulin $\left(\mathrm{AUC}_{\text {Ins }}\right)$ were calculated to reflect islet $\beta$-cell secretion function.

\section{Literature review}

We searched PubMed for manuscripts with full texts in English published prior to February 2020 using key words "Klinefelter syndrome" OR "Klinefelter's syndrome" AND "diabetes mellitus" OR "DM" OR "insulin resistance" OR "hyperglycemia" OR "impaired glucose tolerance" OR "impaired fasting glucose" OR "prediabetes" OR "metabolic syndrome". Two coauthors extracted the medical information of the enrolled patients and the literature using standardized forms independently. If any difference was noted, another coauthor assisted in checking differences between the two coauthors. Twelve studies [9, 11, 20-29] and 10 case reports [30-39] of KS combined with DM or prediabetes were selected.

\section{Statistical analysis}

Continuous variables are expressed as the mean \pm standard deviation. Student's $t$ test was used to compare differences between continuous variables of each group, and the continuous variables that failed the normality test were logarithmically transformed before analysis or tested by the nonparametric test. A $p$-value less than 0.05 was considered significant. All statistical analyses were performed using the statistical program SPSS (version 25, SPSS, Chicago, IL).

\section{Results}

\section{Characteristics of our patients}

Among the $17 \mathrm{KS}$ patients recruited in this study, 35.3\% (6 out 17) of patients were diagnosed with DM, 17.6\% (3 out 17) of patients diagnosed with prediabetes, and $47.1 \%$ (8 out 17) of patients presented insulin resistance with $\mathrm{HOMA}-\mathrm{IR} \geq 2.5$. The clinical data of $\mathrm{KS}$ patients in the PUMCH center are summarized in Table 1 . Of the total of 10 patients presenting with recordings of karyotype results, all presented the classical $47 \mathrm{XXY}$ karyotype. The prevalence of hypertension and dyslipidemia were both increased in the THG-KS group (57.1 and $85.7 \%$ for hypertension and dyslipidemia, respectively) compared with the NGT-KS group (12.5 and $40.0 \%$ for hypertension and dyslipidemia, respectively). Compared with the NGT-KS group, the prevalence of cryptorchidism (14.3\% in the THG-KS group vs $60.0 \%$ in the NGT-KS group) was considerably reduced in the THG-KS group, whereas the ratio of gynecomastia was considerably increased (75.0\% in the THG-KS group vs $50.0 \%$ in the NGT-KS group).

\section{Characteristics of islet $\beta$-cell function in KS and hyperglycemia patients}

KS patients developed abnormal glucose metabolism earlier in life compared with those without KS $(p<0.01)$ (Table 2). The average age of HG-KS was $16.2 \pm 3.3$ years old, and the median age was 17 years old, ranging from 10 to 19 years old. No significant difference in BMI was noted between subjects in the HG group and HG-KS group because we matched BMI when enrolling subjects. Between the two groups with hyperglycemia, FINS and HOMA-IR values were higher in the HG-KS group, and ISImatsuda, QUICKI, IAI and $\mathrm{AUC}_{\mathrm{Glu}} / \mathrm{AUC}_{\mathrm{Ins}}$ were lower in the HG-KS group. However, no significant differences were noted. HOMA- $\beta(p=0.047)$ values were significantly increased in the HG-KS group compared with those with hyperglycemia only. In addition, $\mathrm{AUC}_{\text {Ins }}$ were also increased in the HG-KS group, but no significant differences were noted.

In the comparison between the HG-KS group and NGT group, HOMA-IR $(p=0.032)$ was significantly increased in the HG-KS group, and $\operatorname{ISI}_{\text {matsuda }}(p=0.009)$, QUICKI $(p=0.028)$ and IAI $(p=0.028)$ were significantly decreased. HOMA- $\beta$ ( $p=0.047)$ levels were higher in the HG-KS group. Figure 1 shows the serum insulin and glucose increment curves based on the OGTT in the HG-KS group, HG group and NGT groups. Figure 2 shows the characteristics of insulin sensitivity and islet $\beta$-cell secretion function related parameters in these three groups.

\section{Literature review}

In the literature review, previous studies showed that the prevalence of $\mathrm{DM}$ in $\mathrm{KS}$ patients ranged from 6.8 to $39 \%$, and the prevalence of insulin resistance in KS patients ranged from 24.0 to $38.5 \%$ (Table 3). By summarizing the characteristics of 12 patients in previous case reports (with detailed clinical data) and 9 patients in the THG-KS group (Table 4), we found that the average onset age of hyperglycemia was $27.75 \pm 11.8$ years. Among 16 patients with data of sex hormone records, 15 presented hypergonadotropic hypogonadism, and the remaining patient presented decreased testosterone 
Table 1 Clinical data of patients with Klinefelter Syndrome in PUMCH center

\begin{tabular}{|c|c|c|c|}
\hline Characteristics & KS $(n=17)$ & THG-KS $(n=9)$ & NGT-KS $(n=8)$ \\
\hline Age (y) & $18.6 \pm 5.4$ & $19.6 \pm 6.9$ & $17.5 \pm 2.7$ \\
\hline Height (cm) & $176.9 \pm 11.4$ & $180.7 \pm 11.4$ & $172.5 \pm 9.5$ \\
\hline Body weight (kg) & $72.2 \pm 19.8$ & $76.2 \pm 19.3$ & $67.6 \pm 19.3$ \\
\hline $\mathrm{BMI}\left(\mathrm{kg} / \mathrm{m}^{2}\right)$ & $22.76 \pm 4.48$ & $23.00 \pm 3.77$ & $22.49 \pm 5.17$ \\
\hline $\mathrm{SBP}(\mathrm{mmHg})$ & $128.9 \pm 22.4$ & $144.7 \pm 22.45$ & $115.1 \pm 13.3$ \\
\hline $\mathrm{DBP}(\mathrm{mmHg})$ & $78.5 \pm 20.0$ & $89.9 \pm 21.7$ & $68.5 \pm 11.1$ \\
\hline Testes size (ml) & $2.9 \pm 1.6$ & $1.5 \pm 1.5$ & $2.4 \pm 1.5$ \\
\hline $\mathrm{T}(\mathrm{ng} / \mathrm{ml})$ & $1.84 \pm 1.22$ & $2.24 \pm 1.52$ & $1.43 \pm 0.57$ \\
\hline FSH (IU/L) & $25.88 \pm 16.84$ & $23.30 \pm 12.13$ & $29.32 \pm 25.71$ \\
\hline LH (IU/L) & $29.23 \pm 19.72$ & $30.37 \pm 13.48$ & $27.72 \pm 25.71$ \\
\hline $\mathrm{TC}(\mathrm{mmol} / \mathrm{L})$ & $4.95 \pm 2.00$ & $5.39 \pm 2.30$ & $4.34 \pm 1.22$ \\
\hline $\mathrm{TG}(\mathrm{mmol} / \mathrm{L})$ & $2.22 \pm 1.26$ & $2.57 \pm 1.41$ & $1.73 \pm 0.77$ \\
\hline $\mathrm{LDL}-\mathrm{c}(\mathrm{mmol} / \mathrm{L})$ & $2.79 \pm 1.09$ & $2.94 \pm 1.27$ & $2.61 \pm 0.79$ \\
\hline $\mathrm{HDL}-\mathrm{c}(\mathrm{mmol} / \mathrm{L})$ & $1.02 \pm 0.21$ & $1.05 \pm 0.22$ & $0.99 \pm 0.19$ \\
\hline \multicolumn{4}{|l|}{ Clinical features } \\
\hline Decreased testosterone levels & $14 / 14(100.0 \%)$ & $7 / 7(100.0 \%)$ & $7 / 7(100.0 \%)$ \\
\hline Increased gonadotropin levels & $11 / 13(84.6 \%)$ & $4 / 6(66.7 \%)$ & $7 / 7(100.0 \%)$ \\
\hline Infertility & 4 , others were not considering fertility when collecting the data & 4 & 0 \\
\hline Small testicles (adults) & $4 / 7(57.1 \%)$ & $1 / 3(33.3 \%)$ & $3 / 4(75.0 \%)$ \\
\hline Decreased pubic hair (adults) & $7 / 8(87.5 \%)$ & $3 / 4(75.0 \%)$ & $4 / 4(100.0 \%)$ \\
\hline Gynecomastia & $5 / 11(45.5 \%)$ & $3 / 7(75.0 \%)$ & $2 / 4(50.0 \%)$ \\
\hline Behavioral and intelligence problems & $2 / 13(15.4 \%)$ & $1 / 8(12.5 \%)$ & $1 / 5(20.0 \%)$ \\
\hline Delayed secondary sexual characteristics & 10/13 (76.9\%) & $4 / 7(57.1 \%)$ & $6 / 6(100.0 \%)$ \\
\hline Cryptorchidism & $4 / 12(33.3 \%)$ & $1 / 7(14.3 \%)$ & $3 / 5(60.0 \%)$ \\
\hline Obesity & $4 / 13(30.8 \%)$ & $1 / 7(14.3 \%)$ & $3 / 6(50.0 \%)$ \\
\hline Hypertension & $5 / 17(29.4 \%)$ & $4 / 7(57.1 \%)$ & $1 / 8(12.5 \%)$ \\
\hline Dyslipidemia & $8 / 12(66.7 \%)$ & 6/7 (85.7\%) & $2 / 5(40.0 \%)$ \\
\hline Kayotype & 10/10 (100\%) $47 \mathrm{XXY}$ & & \\
\hline Insulin resistance & 8/17 (47.1\%) & & \\
\hline
\end{tabular}

Abbreviations: PUMCH Peking Union Medical College Hospital; $B M I$ body mass index; SBP systolic blood pressure; $D B P$ diastolic blood pressure; $T$ testosterone; $F S H$ follicle stimulating hormone; $L H$ luteinizing hormone. $T C$ total cholesterol; $T G$ triglyceride; $L D L-c$ low density lipoprotein cholesterol; $H D L-c$ high density lipoprotein cholesterol. Insulin resistance was defined as HOMA $\geq 2.5$. HOMA was calculated as a measure of insulin resistance as follows: [fasting blood glucose (mmol/L) $\times$ fasting insulin $(\mu \mathrm{lU} / \mathrm{mL})] / 22.5$

levels. The most common clinical feature related to KS was decreased testosterone levels $(100.0 \%)$ followed by increased gonadotropin levels $(93.8 \%)$, decreased pubic hair $(88.9 \%$ in adults), small testicles $(83.3 \%$ in adults), delayed secondary sexual characteristics $(63.6 \%)$, behavioral and intelligence problems (31.3\%), gynecomastia (28.6\%) and cryptorchidism (20.0\%). All patients with infertility plans complained of infertility. Regarding karyotypes, $71.4 \%$ patients were $47 \mathrm{XXY}, 14.3 \%$ were $46 \mathrm{XY}$ / $47 \mathrm{XXY}$ and $14.3 \%$ were $49 \mathrm{XXXXY}$.

The specific clinical data of patients with hyperglycemia in both the PUMCH center and previous literature are summarized in Supplementary Table 1.

\section{Discussion}

In this study, we summarized the clinical features of KS patients in a single Chinese hospital center and evaluated the characteristics of islet $\beta$-cell function in $\mathrm{KS}$ and hyperglycemia patients compared with hyperglycemia patients without KS and NGT subjects. The prevalence of DM in KS patients in the PUMCH center was $35.3 \%$. This value was much higher than the prevalence of DM in the general population, which was $10.4 \%$ in China according to the guidelines of the Chinese Diabetes Society published in 2017 and $14.3 \%$ in the United States [40]. KS is considered as a state of "prediabetes" [41]. In addition, associations between KS and impaired glucose 
Table 2 Characteristics of patients of hyperglycemia with or without KS and normal glucose tolerance subjects

\begin{tabular}{|c|c|c|c|c|c|}
\hline & HG-KS $(n=5)$ & HG $(n=5)$ & NGT $(n=5)$ & $p$ value & \\
\hline & & & & HG-KS vs HG & HG-KS vs NGT \\
\hline Age (y) & $16.2 \pm 3.3$ & $41.2 \pm 2.1$ & $34.0 \pm 6.2$ & $0.008^{*}$ & $0.009^{*}$ \\
\hline BMI $\left(\mathrm{kg} / \mathrm{m}^{2}\right)$ & $22.68 \pm 2.97$ & $24.82 \pm 2.00$ & $22.08 \pm 2.50$ & 0.600 & 0.754 \\
\hline FBG (mmol/L) & $5.90 \pm 2.04$ & $7.54 \pm 3.21$ & $5.22 \pm 0.37$ & 0.251 & 0.754 \\
\hline FINS ( $\mu \mid \mathrm{U} / \mathrm{ml})$ & $29.22 \pm 26.00$ & $12.66 \pm 7.01$ & $8.89 \pm 2.62$ & 0.076 & $0.009^{*}$ \\
\hline HOMA-IR & $7.47 \pm 7.05$ & $5.22 \pm 5.47$ & $2.10 \pm 0.75$ & 0.175 & $0.032^{*}$ \\
\hline HOMA- $\beta$ & $346.24 \pm 202.59$ & $76.64 \pm 28.69$ & $103.56 \pm 20.07$ & $0.047^{*}$ & $0.047^{*}$ \\
\hline ISImatsuda & $35.98 \pm 13.87$ & $61.17 \pm 23.05$ & $88.29 \pm 29.67$ & 0.076 & $0.009^{*}$ \\
\hline QUICKI & $0.30 \pm 0.03$ & $0.32 \pm 0.03$ & $0.35 \pm 0.02$ & 0.175 & $0.028^{*}$ \\
\hline$|A|$ & $0.01 \pm 0.005$ & $0.02 \pm 0.008$ & $0.02 \pm 0.008$ & 0.175 & $0.028^{*}$ \\
\hline$A \cup C_{\text {Ins }}$ & $423.89 \pm 254.66$ & $146.06 \pm 62.23$ & $179.62 \pm 69.83$ & 0.175 & 0.175 \\
\hline$A \cup C_{G l u} / A \cup C_{I n s}$ & $0.17 \pm 0.25$ & $0.31 \pm 0.17$ & $0.14 \pm 0.05$ & 0.117 & 0.175 \\
\hline
\end{tabular}

Statistical difference is along the row and $p<0.05$ was considered significant

*represents significant difference between two groups

Abbreviations: KS Klinefelter syndrome, HG hyperglycemia, NGT normal glucose tolerance, BMI body mass index, FBG fasting blood glucose, FINS fasting serum insulin, HOMA-IR homeostasis model assessment of insulin resistance, HOMA- $\beta$ homeostasis model assessment of $\beta$-cell function, ISI matsuda insulin sensitivity index proposed by Matsuda et al., QUICKI quantitative insulin sensitivity check index, IAI insulin action index, $A U C_{I n s}$ area under curve of insulin, $A U C_{G I U} / A U C_{I n s}$ ratio of area under curve of glucose and insulin

tolerance and DM have been reported, and several possible mechanisms of DM have been proposed. Low levels of testosterone are proposed to correlate with the increased prevalence of insulin resistance and DM in males [42, 43]. In several studies in KS patients, testosterone deficiency was identified as an independent predictor for insulin resistance and metabolic syndrome $[10,20]$, and the effects of testosterone replacement therapy (TRT) on ameliorating hyperglycemia and insulin resistance [44] were observed. The gene dosage effect from the extra copies of X chromosomes was hypothesized to be another factor [6] based on the evidence of the close relationship between karyotypes and DM $[6,9]$, and the level of insulin resistance [45]. Autoimmune abnormalities may also be involved given the presence of T1DM-related autoantibodies in some KS patients [10, 46]. Other mechanisms, such as changes in body composition, inflammation status [11], socioeconomic factors [2], high triglyceride levels, fatty liver and acute pancreatitis [6], might also play important roles in the development of DM in KS patients. However, the specific pathogenesis remains to be elucidated, and further large, long-term, prospective, randomized, controlled studies are needed to clarify whether and to what extent the above factors may affect glycemic metabolism in KS patients.

We found that hyperglycemia developed earlier in life in KS patients compared with those without KS, which was consistent with previous observations that found that the course of DM in KS patients was approximately 30 years old [10]. Insulin sensitivity was lower in hyperglycemic KS patients compared with hyperglycemic patients without KS, whereas HOMA- $\beta$ levels were significantly higher. These results indicated better competence of insulin compensatory secretion. Insulin resistance was considered the major characteristic in KS patients with DM. Bojesen et al. [11] calculated insulin sensitivity using the HOMA model and showed a
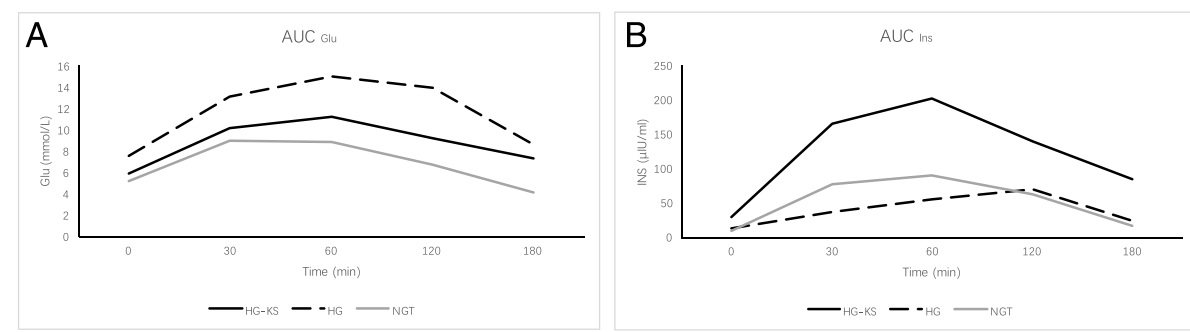

Fig. 1 The increment curves of serum glucose (A) and insulin (B) during OGTT in HG-KS group, HG group and NGT group. Abbreviations: OGTT Oral glucose tolerance test, KS Klinefelter syndrome, HG hyperglycemia, NGT normal glucose tolerance, AUC area under curve, Glu glucose, Ins insulin 

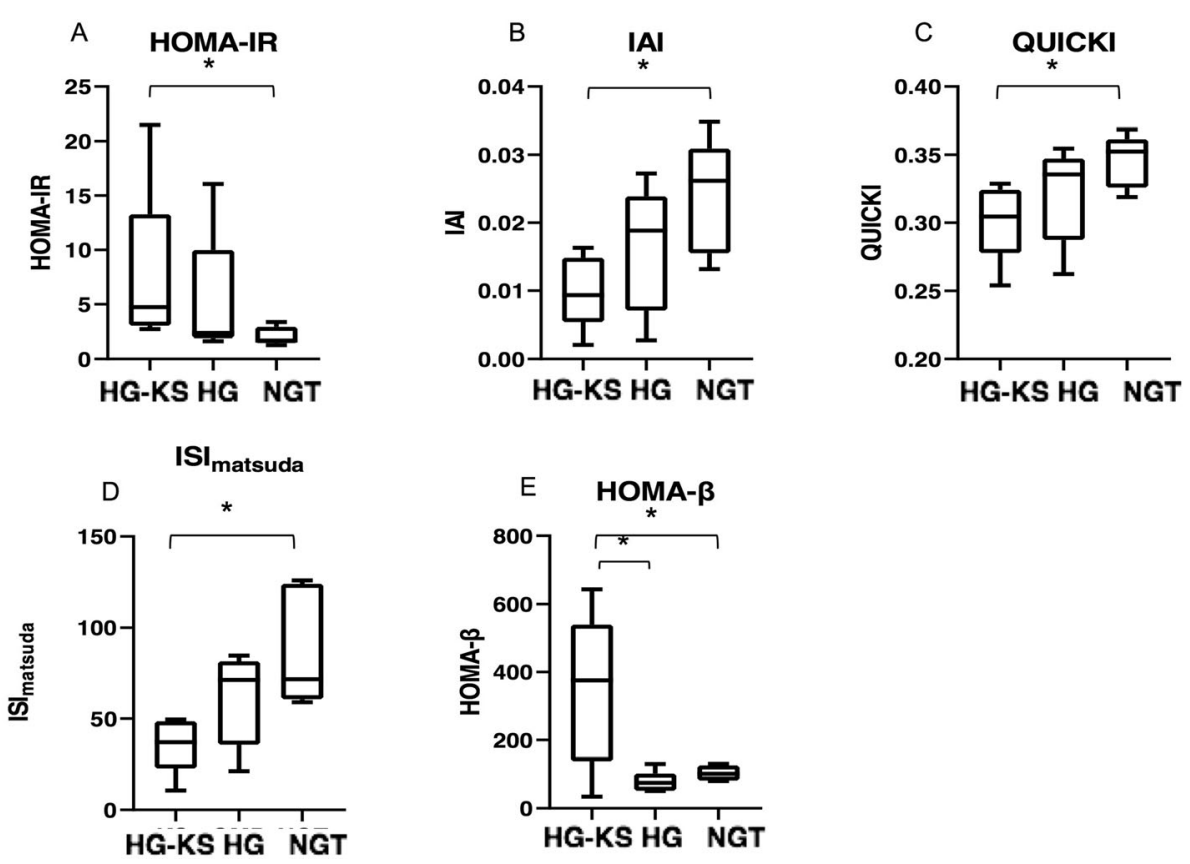

Fig. 2 Boxplots of HOMA-IR (A), IAI (B), QUICKI (C), ISImatsuda (D) and HOMA- $\beta$ (E) in HG-KS group, HG group and NGT group. * represented significant difference $(p<0.05)$ between two groups. HOMA-IR $(\mathbf{A})(p=0.032)$ was significantly increased in HG-KS group compared to NGT group, IAI (B) $(p=0.028)$, QUICKI (C) $(p=0.028)$ and ISImatsuda (D) $(p=0.009)$ was significantly decreased in HG-KS group compared to NGT. HOMA- $\beta$ (E) was significantly increased in HG-KS group compared to both HG $(p=0.030)$ and NGT $(p=0.044)$ groups. Abbreviations: KS Klinefelter syndrome, HG hyperglycemia, NGT normal glucose tolerance, HOMA-IR homeostasis model assessment of insulin resistance, HOMA- $\beta$ homeostasis model assessment of $\beta$-cell function, ISImatsuda insulin sensitivity index proposed by Matsuda et al., QUICKI quantitative insulin sensitivity check index, IAl insulin action index

significantly decreased insulin sensitivity but a significantly increased islet $\beta$-cell secretion function in KS patients. Pei et al. [47] observed elevated insulin resistance in KS patients using the area under the curve of serum insulin after a 75-g oral glucose load and insulin suppression test. Using the gold standard, the hyperinsulinemic euglycemic clamp test, Lee et al. [48] demonstrated that impaired peripheral insulin resistance was the underlying mechanism of impaired glucose tolerance in Korean patients with KS. In contrast, Yesilova et al. [21] discovered that plasma insulin levels of KS patients were significantly elevated, but insulin-mediated glucose disposal values were not reduced compared with the controls. These researchers concluded that hyperinsulinemia may be the primary metabolic abnormality rather than insulin resistance. Our results found that insulin resistance and a compensatory increase in insulin secretion exist in KS patients, and the increased islet $\beta$-cell secretion function was statistically significant compared with those patients with hyperglycemia but without KS.

Best practices for hypoglycemic therapy in hyperglycemic KS patients have still not been established. The effects of TRT on the improvement of glucose control remain controversial. Some clinical trials observed improvement in
HbA1c levels after TRT $[44,49]$, whereas others reported no improvement [50-52]. In particular, improvements in insulin sensitivity by TRT were observed in obese hypogonadal patients but not lean patients [53]. According to previous evidence, populations with lower testosterone levels tend to have a higher proportion of body fat, which results in impaired insulin sensitivity. After TRT, improvement in the ratio of fat and muscle composition could benefit glucose and lipid metabolism rather than the direct effect of TRT. Insulin therapy is a common strategy in KS patients with DM. In the case review in Japan, among 895 Japanese KS patients reported in literature up to 2001, 61 patients were diagnosed with DM, and at least 20 patients were treated with insulin preparations. However, glycemic control was poor with an HbA1c level of $10.6 \%$ [23], reflecting less effective in glycemic control of insulin therapy among KS and DM patients. Based on the results of the changes in insulin sensitivity and islet $\beta$-cell secretion function in our study, we found that KS patients with hyperglycemia presented with similar insulin resistance levels but better islet $\beta$-cell secretion function than those without KS. These findings suggested that insulin preparations might not represent the best choice for KS patients with hyperinsulinemia given that hyperinsulinemia and insulin 
Table 3 Literature review of studies evaluating diabetes mellitus or insulin resistance in Klinefelter syndrome

\begin{tabular}{|c|c|c|c|c|c|c|c|c|}
\hline $\begin{array}{l}\text { Author, } \\
\text { year (ref.) }\end{array}$ & $\begin{array}{l}\text { Number of } \\
\text { patients }\end{array}$ & $\begin{array}{l}\text { Age } \\
\text { (year) }\end{array}$ & $\begin{array}{l}\text { BMI } \\
(\mathrm{kg} / \\
\left.\mathrm{m}^{2}\right)\end{array}$ & DM (\%) & $\begin{array}{l}\text { IFG } \\
\text { (\%) }\end{array}$ & IR (\%) & $\begin{array}{l}\text { Diagnosed criteria } \\
\text { of IR }\end{array}$ & Karyotype \\
\hline $\begin{array}{l}\text { Han, } 2016 \\
{[20]}\end{array}$ & 376 & 32 & $\begin{array}{l}24.7 \pm \\
3.9\end{array}$ & $28(12.8 \%)$ & $\begin{array}{l}57 \\
(26.0 \%)\end{array}$ & - & - & $\begin{array}{l}47 X X Y, 354 ; 48 X X X Y, 2 ; 48 X X Y Y, 1 ; 46 \\
X Y / 47 X X Y, 13 ; 47 X X Y / 48 X X X Y / 46 \\
X Y, 3 ; 47 X X Y / 46 X Y / 46 X X, 1 ; 47 X X Y / \\
48 X X X Y, 1 ; 47 X X, \text { inv. (Y), } 1\end{array}$ \\
\hline $\begin{array}{l}\text { Yesilova, } \\
2005[21]\end{array}$ & 13 & 22 & $\begin{array}{l}23.7 \pm \\
4.9\end{array}$ & - & - & $38.5 \%$ & $\begin{array}{l}\text { Glucose disposal rates } \\
<4.53 \mathrm{mg} / \mathrm{kg} / \mathrm{min} \text { in } \\
\text { hyperinsulinemic } \\
\text { euglycemic clamp }\end{array}$ & All $47 X X Y$ \\
\hline $\begin{array}{l}\text { Bojesen, } \\
2006[11]\end{array}$ & $\begin{array}{l}70 \text { ( } 35 \\
\text { without } \\
\text { TRT/35 with } \\
\text { treatment) }\end{array}$ & $35 / 39$ & $\begin{array}{l}27.3 / \\
25.1\end{array}$ & $\begin{array}{l}3(8.5 \%) / 4 \\
(11.4 \%)\end{array}$ & $\begin{array}{l}6 \\
(17.1 \%) ; \\
7 \\
(20.0 \%)\end{array}$ & - & - & - \\
\hline $\begin{array}{l}\text { Falhammar, } \\
2018 \text { [22] }\end{array}$ & 224 & 22 & $\begin{array}{l}26.1 \pm \\
5.3\end{array}$ & $9.10 \%$ & - & - & - & $\begin{array}{l}47 \mathrm{XXY}, 204 ; 47 \mathrm{XXY} / 46 \mathrm{XY}, 6 ; 47 \mathrm{XXY} / \\
46 \mathrm{XX}, 3 \text {; Others and unknown, 5; } 46 \\
\mathrm{XX} \text { testicular males, } 6 .\end{array}$ \\
\hline $\begin{array}{l}\text { Ota, } 2002 \\
{[23]}\end{array}$ & 895 & 43 & $\begin{array}{l}21.5 \pm \\
4.44\end{array}$ & $61(6.8 \%)$ & - & - & - & $\begin{array}{l}47 X X Y, 40 ; 46 X Y / 47 X X Y, 9 ; 48 X X Y Y, \\
2 ; 47 X X Y / 48 X X X Y / 46 X Y, 1 ; 47 X X Y / 46 \\
X Y / 46 X X, 1 ; \text { unknown, 8. }\end{array}$ \\
\hline $\begin{array}{l}\text { Bardsley, } \\
2011 \\
{[29]}\end{array}$ & $\begin{array}{l}89 \\
\text { Prepubertal } \\
\text { Boys }\end{array}$ & 8 & - & 0 & 0 & $20(24 \%)$ & HOMA $\geq 2.5$ & $\begin{array}{l}47 \mathrm{XXY}, 84 ; 48 \mathrm{XXYY}, 1 ; 47 \mathrm{XXY} / 46 \mathrm{XY} \\
2 ; 46 \mathrm{XX} \text { translocation, } 1 .\end{array}$ \\
\hline $\begin{array}{l}\text { Jackson, } \\
1966[24]\end{array}$ & 8 & - & - & - & $\begin{array}{l}1 \\
(12.5 \%)\end{array}$ & - & - & $47 X X Y, 2$; others unknown. \\
\hline $\begin{array}{l}\text { Becker, } \\
1966[25]\end{array}$ & 50 & 38 & - & $5(10.0 \%)$ & - & - & - & - \\
\hline $\begin{array}{l}\text { Pasquali, } \\
2013[26]\end{array}$ & 69 & 31 & 27.5 & 3 & 16 & - & - & - \\
\hline $\begin{array}{l}\text { Nielsen, } \\
1969[9]\end{array}$ & 31 & - & - & $\begin{array}{l}12(39 \%) ; \\
\text { especially } 47 \\
X X Y / 46 X Y, 4 ; 47 \\
X X Y, 5 ; 48 \\
X X X Y, 3 .\end{array}$ & - & - & - & $\begin{array}{l}47 X X Y / 46 X Y, 4 ; 47 X X Y, 24 ; 48 X X X Y \\
\text { 3. }\end{array}$ \\
\hline $\begin{array}{l}\text { Davis, } 2016 \\
{[27]}\end{array}$ & $\begin{array}{l}96 \\
\text { Prepubertal } \\
\text { Boys }\end{array}$ & - & - & 0 & 0 & $\begin{array}{l}9(33.3 \%), \\
\text { only } 27 \\
\text { patients } \\
\text { calculated } \\
\text { for HOMA }\end{array}$ & HOMA $\geq 2.5$ & $\begin{array}{l}47 \mathrm{XXY}, 88 ; 46 \mathrm{XY} / 47 \mathrm{XXY}, 2 ; 48 \mathrm{XXXY}, 1 ; \\
48 \mathrm{XXYY}, 1 ; 46 \mathrm{XX}+\text { SRYtrans, } 1 .\end{array}$ \\
\hline $\begin{array}{l}\text { Davis, } 2017 \\
{[28]}\end{array}$ & $\begin{array}{l}93 \\
\text { Prepubertal } \\
\text { Boys }\end{array}$ & - & - & - & 1 & - & - & $\begin{array}{l}47 X X Y, 89 ; 46 X Y / 47 X X Y, 2 ; 48 X X X Y \\
\text { or } 48 X X Y Y, 3 .\end{array}$ \\
\hline
\end{tabular}

Abbreviations: TRT testosterone replacement therapy, $T$ testosterone, $F S H$ follicle stimulating hormone, $L H$ luteinizing hormone, $B M I$ body mass index, $D M$ diabetes mellitus, IFG impaired fasting glucose, FBG fasting blood glucose, HbA1c hemoglobin A1c, HOMA homeostatic model assessment, IR insulin resistance. Continuous variables were expressed as mean or mean \pm standard deviation (SD). HOMA was calculated as a measure of insulin resistance as follows: [fasting blood glucose $(\mathrm{mmol} / \mathrm{L}) \times$ fasting insulin $(\mu \mathrm{IU} / \mathrm{mL})] / 22.5$

resistance would result in an increased dosage of insulin preparations and reduce the curative effects. Further weight gain following an increased insulin dosage would aggravate insulin resistance. From this point of view, oral hypoglycemic drugs that improve insulin sensitivity might be considered first for those with existing islet $\beta$-cell secretion function. For KS patients with hyperglycemia, we recommended individualized hypoglycemia drug selection after evaluating islet $\beta$-cell function rather than taking insulin therapy at first.
Based on the results of clinical features associated with KS, those patients with hyperglycemia were more likely to present gynecomastia, which was consistent with the findings of lower testosterone levels compared with those with NGT. The prevalence of cryptorchidism was lower in hyperglycemia patients, whereas the prevalence of behavioral and intelligence problems was increased. We also found an increased frequency of development of other metabolic diseases in hyperglycemia and KS patients, including hypertension and dyslipidemia. These 
Table 4 Abnormalities associated with Klinefelter syndrome and hyperglycemia combined PUMCH center and previous case reports

\begin{tabular}{ll}
\hline Characteristics & Patients $(\boldsymbol{n = 2 1 )}$ \\
\hline Age & $27.75 \pm 11.8$ \\
Clinical features & \\
Decreased testosterone levels & 16 out $16(100.0 \%)$ \\
Increased gonadotropin levels & 15 out $16(93.8 \%)$ \\
Infertility & 7 adults with recording \\
Small testicles (adults) & 10 out $12(83.3 \%)$ \\
Decreased pubic hair (adults) & 8 out $9(88.9 \%)$ \\
Gynecomastia & 4 out $14(28.6 \%)$ \\
Behavioral and intelligence problems & 5 out $16(31.3 \%)$ \\
Delayed secondary sexual characteristics & 7 out $11(63.6 \%)$ \\
Cryptorchidism & 3 out $15(20.0 \%)$ \\
Obesity & 9 out $18(50.0 \%)$ \\
Hypertension & 8 out $15(53.3 \%)$ \\
Hyperglycemia & 9 out $13(69.2 \%)$ \\
Karyotype & 10 out $14(71.4 \%), 47$ XXY; $2 / 14(14.3 \%), 46$ XY/47 XXY; 2 out $14(14.3 \%), 49$ XXXXY \\
Prediabetes & 3 out $21(14.3 \%)$ \\
Diabetes mellitus & 18 out $21(85.7 \%)$ \\
Insulin resistance parameters & 8 out $10(80.0 \%)$ \\
\hline
\end{tabular}

Abbreviations: PUMCH Peking Union Medical College Hospital

Insulin resistance was defined as $\mathrm{HOMA} \geq 2.5$. HOMA was calculated as a measure of insulin resistance as follows: [fasting blood glucose (mmol/L) $\times$ fasting insulin $(\mu \mathrm{lU} / \mathrm{mL})] / 22.5$

results confirmed that other metabolic factors, including blood pressure and serum lipid levels, may have effects on glucose metabolism in KS patients.

This study has some limitations. First, KS is a rare disease, and this is a retrospective study in a single Chinese center. Thus, the sample size was small. Second, the clinical information was limited, and data on some clinical features were missing. Third, the age of patients in the HG-KS group did not match that in the HG group because adolescents with type 2 diabetes mellitus were mostly obese, thus the BMI values of these patients could not be matched with those of KS patients.

\section{Conclusions}

In conclusion, we found that KS patients develop hyperglycemia earlier in life.

compared with those without KS. Patients with KS and hyperglycemia were more likely to have other metabolic diseases and may have different frequencies of developing KS-related symptoms than NGT KS patients. The prevalence of gynecomastia and behavioral and intelligence problems was higher, whereas the prevalence of cryptorchidism was lower. KS patients with hyperglycemia tended to have decreased insulin sensitivity and hyperinsulinemia and increased insulin secretion compared with hyperglycemia patients without KS. Based on the characteristics of glucose metabolism in KS patients, we recommend evaluating islet $\beta$-cell function before hypoglycemic treatment, given that oral hypoglycemic drugs may be the first choice for those still with islet $\beta$ cell secretion function rather than insulin preparations, because decreased insulin sensitivity may have a poor hypoglycemic effect.

\section{Abbreviations}

KS: Klinefelter syndrome; FSH: follicle stimulating hormone; LH: luteinizing hormone; DM: diabetes mellitus; OGTT: oral glucose tolerance test; BMI: body mass index; PUMCH: Peking Union Medical College Hospital; NGT: normal glucose tolerance; FBG: fasting blood glucose; HbA1c: glycosylated hemoglobin A1c; PBG: postprandial blood glucose; SBP: systolic blood pressure; DBP: diastolic blood pressure; TG: triglyceride; HDL-c: high density lipoprotein cholesterol level; QUICKI: Quantitative Insulin Sensitivity Check Index; ISImatsuda: insulin sensitivity index proposed by Matsuda et al.; $|A|$ : the reciprocal of the product of fasting serum insulin and blood glucose which named insulin action index; $A \cup C_{G I U} / A \cup C_{\text {Ins: }}$ the ratio of area under curve of glucose and insulin; HOMA-IR: homeostasis model assessment of insulin resistance; HOMA- $\beta$ : homeostasis model assessment of $\beta$-cell function; TRT: testosterone replacement therapy; T1DM: type 1 diabetes mellitus

\section{Supplementary Information}

The online version contains supplementary material available at https://doi. org/10.1186/s12902-021-00893-5.

Additional file 1. Supplementary Table 1. Characteristics of patients in our center and previous case reports

\section{Acknowledgments}

All authors follow the ICMJE requirements on privacy, and all participants have provided written consent for the inclusion of material pertaining to 
themselves. Participants also acknowledge that they cannot be identified via the paper and that they have been fully anonymized.

\section{Authors' contributions}

Conceptualization: TY and SL; Investigation: YD, YT and YF; Methodology: TY and WZ; Clinical data collection: SL, SS, SC and LW; Writing - original draft: TY and SL; Writing - review editing: TY and WZ; Supervision: WZ. All authors read and approved the final manuscript.

\section{Funding}

This study was funded by the CAMS Innovation Fund for Medical Science (CIFMS) the Non-profit Central Research Institute Fund of Chinese Academy of Medical Sciences (No: 2016-I2M-4-001) (to Tao Yuan), "13th Five-Year" National Science and Technology Major Project for New Drugs (No: 2019ZX09734001) (to Weigang Zhao), and the Non-profit Central Research Institute Fund of Chinese Academy of Medical Sciences (No. 2017PT32020, No. 2018PT32001) (to Tao Yuan).

\section{Availability of data and materials}

The data generated during and/or analysed during the current study are available from the corresponding author on reasonable request.

\section{Declarations}

\section{Ethics approval and consent to participate}

This study was approved by the Peking Union Medical College Hospital (PUMCH) Ethics Committee and followed the ethical standards of the responsible committee on human experimentation and with the Helsinki Declaration of 1964, as revised in 2013. All participants signed written informed consent and provided consent for publication if any identifying information was included in the manuscript.

For all minors involved in the study, their legally authorized representatives provided informed consent.

\section{Consent for publication}

The authors affirm that all individual participants provided informed consent for publication of the data. Additional informed consent was obtained from all individual participants for whom identifying information was included in this article.

Informed consent of minors was also provided by their legally authorized representatives provide.

\section{Competing interests}

The authors declare that the research was conducted in the absence of any commercial or financial relationships that could be construed as a potentia conflict of interest.

\section{Author details}

${ }^{1}$ Department of Endocrinology, Key Laboratory of Endocrinology of National Health Commission, Peking Union Medical College Hospital, Peking Union Medical College \& Chinese Academy of Medical Sciences, No. 1 Shuaifuyuan Street, Dongcheng District, Beijing0086 100730China. ${ }^{2}$ Department of Pharmacy, Peking Union Medical College Hospital, Peking Union Medical College \& Chinese Academy of Medical Sciences, No.1 Shuaifuyuan Street, Dongcheng District, Beijing 0086 100730, China.

\section{Received: 5 February 2021 Accepted: 13 October 2021}

\section{Published online: 01 December 2021}

\section{References}

1. Kanakis GA, Nieschlag E. Klinefelter syndrome: more than hypogonadism. Metabolism. 2018:86:135-44. https://doi.org/10.1016/j.metabol.2017.09.017.

2. O'Connor MJ, Snyder EA, Hayes FJ. Klinefelter Syndrome and Diabetes. Curr Diab Rep. 2019;19(9):71. https://doi.org/10.1007/s11892-019-1197-3.

3. Herlihy AS, McLachlan RI. Screening for Klinefelter syndrome. Curr Opin Endocrinol Diabetes Obes. 2015;22(3):224-9. https://doi.org/10.1097/MED. 0000000000000154

4. Ishikawa T, Yamaguchi K, Kondo Y, Takenaka A, Fujisawa M. Metabolic syndrome in men with Klinefelter's syndrome. Urology. 2008;71(6):1109-13. https://doi.org/10.1016/j.urology.2008.01.051.
5. Gravholt CH, Jensen AS, Høst C, Bojesen A. Body composition, metabolic syndrome and type 2 diabetes in Klinefelter syndrome. Acta Paediatr. 2011; 100(6):871-7. https://doi.org/10.1111/j.1651-2227.2011.02233.x.

6. Jiang-Feng M, Hong-Li X, Xue-Yan W, Min N, Shuang-Yu L, Hong-Ding X, et al. Prevalence and risk factors of diabetes in patients with Klinefelter syndrome: a longitudinal observational study. Fertil Steril. 2012;98(5):1331-5. https://doi.org/10.1016/j.fertnstert.2012.07.1122.

7. Calogero $A E$, et al. Klinefelter syndrome: cardiovascular abnormalities and metabolic disorders. J Endocrinol Investig. 2017;40(7):705-12. https://doi. org/10.1007/s40618-017-0619-9.

8. Gravholt CH, Chang S, Wallentin M, Fedder J, Moore P, Skakkebaek A. Klinefelter syndrome: integrating genetics, neuropsychology, and endocrinology. Endocr Rev. 2018;39(4):389-423. https://doi.org/10.1210/er.2 017-00212.

9. Nielsen J, Johansen $\mathrm{K}, \mathrm{Y}$ de $\mathrm{H}$. Frequency of diabetes mellitus in patients with Klinefelter's syndrome of different chromosome constitutions and the XYY syndrome. Plasma insulin and growth hormone level after a glucose load. J Clin Endocrinol Metab. 1969;29(8):1062-73.

10. Salzano A, D'Assante R, Heaney LM, Monaco F, Rengo G, Valente P, et al, Klinefelter syndrome, insulin resistance, metabolic syndrome, and diabetes: review of literature and clinical perspectives. Endocrine, 2018. 61: 194-203, 2, https://doi.org/10.1007/s12020-018-1584-6.

11. Bojesen A, Juul S, Birkebaek NH, et al. Morbidity in Klinefelter syndrome: a Danish register study based on hospital discharge diagnoses. J Clin Endocrinol Metab. 2006;91(4):1254-60. https://doi.org/10.1210/jc.2005-0697.

12. Swerdlow AJ, Higgins CD, Schoemaker MJ, Wright AF, Jacobs PA. United Kingdom clinical cytogenetics group. Mortality in patients with Klinefelter syndrome in Britain: a cohort study. J Clin Endocrinol Metab. 2005;90(12): 6516-22. https://doi.org/10.1210/jc.2005-1077.

13. American Diabetes Association. 2. Classification and Diagnosis of Diabetes: Standards of Medical Care in Diabetes-2019. Diabetes Care. 2019;42(Suppl 1):S13-S28. https://doi.org/10.2337/dc19-S002.

14. Caterson ID, Inoue S, Zimmet PZ. The Asia-Pacific perspective: redefining obesity and Its Treatment[J]. Www.iotf.org/asiapacific. 2000.

15. Grundy SM, Brewer HB Jr, Cleeman JI, Smith SC Jr, Lenfant C, American Heart Association, et al. Definition of metabolic syndrome: report of the National Heart, Lung, and Blood Institute/American Heart Association conference on scientific issues related to definition. Circulation. 2004;109(3): 433-8. https://doi.org/10.1161/01.CIR.0000111245.75752.C6.

16. Katz A, Nambi SS, Mather $K$, et al. Quantitative insulin sensitivity check index: a simple, accurate method for assessing insulin sensitivity in humans. J Clin Endocrinol Metab. 2000;85(7):2402-10. https://doi.org/10.1210/jcem. 85.7.6661

17. Matsuda M, RA DF. Insulin sensitivity indices obtained from Oral glucose tolerance testing: comparison with the euglycemic insulin clamp. Diabetes Care. 1999;22(9):1462-70. https://doi.org/10.2337/diacare.22.9.1462.

18. Antuna-Puente B, Disse E, Rabasa-Lhoret R, Laville M, Capeau J, Bastard JP. How can we measure insulin sensitivity/resistance. Diabetes Metab. 2011; 37(3):179-88. https://doi.org/10.1016/j.diabet.2011.01.002.

19. Matthews DR, Hosker JP, Rudenski AS, et al. Homeostasis model assessment: insulin resistance and beta cell function from fasting plasma glucose and insulin concentrations in man. Diabetologia. 1985;28(7):412-9. https://doi. org/10.1007/BF00280883.

20. Han SJ, Kim K, Kim W, et al. Obesity and hyperglycemia in Korean men with Klinefelter syndrome: the Korean Endocrine Society Registry. Endocrinol Metab (Seoul). 2016;31(4):598-603. https://doi.org/10.3803/EnM.2016.31.4. 598.

21. Yesilova Z, Oktenli C, Sanisoglu SY, Musabak U, Cakir E, Ozata M, et al. Evaluation of insulin sensitivity in patients with Klinefelter's syndrome: a hyperinsulinemic euglycemic clamp study. Endocrine. 2005;27(1):11-5. https://doi.org/10.1385/ENDO:27:1:011.

22. Falhammar H, Claahsen-van der Grinten H, Reisch N, Slowikowska-Hilczer J, Nordenström A, Roehle R, et al. Health status in 1040 adults with disorders of sex development (DSD): a European multicenter study. Endocr Connect. 2018;7(3):466-78. https://doi.org/10.1530/EC-18-0031

23. Ota K, Suehiro T, Ikeda Y, Arii K, Kumon Y, Hashimoto K. Diabetes mellitus associated with Klinefelter's syndrome: a case report and review in Japan. Intern Med. 2002:41(10):842-7. https://doi.org/10.2169/internalmedicine.41.842.

24. Jackson IM, Buchanan KD, MT MK, Prentice CR. Carbohydrate metabolism in Klinefelter's syndrome. J Endocrinol. 1966:35(2):169-72. https://doi.org/10.1 677/joe.0.0350169. 
25. Becker KL, DL H, Underdahl LO, Mason HL. Klinefelter's syndrome: Clinical and laboratory findings in 50 patients. Arch Intern Med. 1966;118(4):314-21. https://doi.org/10.1001/archinte.1966.00290160014004.

26. Pasquali D, Arcopinto M, Renzullo A, Rotondi M, Accardo G, Salzano A, et al. Cardiovascular abnormalities in Klinefelter syndrome. Int J Cardiol. 2013; 168(2):754-9. https://doi.org/10.1016/j.ijcard.2012.09.215.

27. Davis S, Lahlou N, Bardsley M, Temple MC, Kowal K, Pyle L, et al. Gonadal function is associated with cardiometabolic health in pre-pubertal boys with Klinefelter syndrome. Andrology. 2016;4(6):1169-77. https://doi.org/1 0.1111 /andr.12275

28. Davis SM, Cox-Martin MG, Bardsley MZ, Kowal K, Zeitler PS, Ross JL. Effects of Oxandrolone on Cardiometabolic health in boys with Klinefelter syndrome: a randomized controlled trial. J Clin Endocrinol Metab. 2017; 102(1):176-84. https://doi.org/10.1210/jc.2016-2904.

29. Bardsley MZ, Falkner B, Kowal K, Ross JL. Insulin resistance and metabolic syndrome in prepubertal boys with Klinefelter syndrome. Acta Paediatr. 2011;100(6):866-70. https://doi.org/10.1111/j.1651-2227.2011.02161.x.

30. Wei L, Liu Y, Sun S, Tang Y, Chen S, Song G. Case report of $49, X X X X Y$ syndrome with cleft palate, diabetes, hypothyroidism, and cataracts. Medicine (Baltimore). 2019;98(39):e17342. https://doi.org/10.1097/MD. 0000000000017342.

31. Hara S, Anderson RS, Bland W, Crump EP. Simultaneous occurrence of diabetes mellitus and Klinefelter's syndrome in two patients. J Natl Med Assoc. 1970;62(1):42-5

32. Yoshiuchi I, Itoh N, Nakano M, Tatsumi C, Yokoyama K, Matsuyama T. Case report of Klinefelter's syndrome with severe diabetes, dyslipidemia, and stroke: the effect of pioglitazone and other anti-inflammatory agents on interleukin-6 and -8, tumor necrosis factor-alpha, and Creactive protein. Diabetes Care. 2006;29(8):1981. https://doi.org/10.2337/ dc06-0651.

33. Gotoh M, Nakano J, Midorikawa S, Niimura S, Ono Y, Mizuno K. Multiple endocrine disorders and Rathke's cleft cyst with Klinefelter's syndrome: a case report. Endocr J. 2002;49(4):523-9. https://doi.org/10.1507/endocrj.49.523.

34. Yamaguchi AV, Costanzo PR, Peuchot VA. Testosterone Replacement Therapy and the Risk of Hypoglycemia. Case Rep Endocrinol. 2019;2019: 9616125. https://doi.org/10.1155/2019/9616125.

35. Kim HJ, Kim D, Shin JM, Chung HK, Lee G. 49,XXXXY syndrome with diabetes mellitus. Horm Res. 2006;65(1):14-7. https://doi.org/10.1159/ 000090327

36. Seno $Y$, Iwasaki $Y$, Aizawa-Abe $M$, et al. Facilitating screening of Klinefelter syndrome among patients with diabetes. J Diabetes Investig. 2019.

37. Isobe K, Niwa T, Ohkubo M, Ohba M, Shikano M, Watanabe Y. Klinefelter's syndrome accompanied by diabetes mellitus and diabetes insipidus. Intern Med. 1992;31(7):917-21.

38. Tojo K, Kaguchi Y, Tokudome G, et al. 47 XXY/46 XY mosaic Klinefelter's syndrome presenting with multiple endocrine abnormalities. Intern Med. 1996;35(5):396-402. https://doi.org/10.2169/internalmedicine.35.396.

39. Ayli M, Ertek S. Serious venous thromboembolism, heterozygous factor $V$ Leiden and prothrombin G20210A mutations in a patient with Klinefelter syndrome and type 2 diabetes. Intern Med. 2009;48(18):1681-5. https://doi. org/10.2169/internalmedicine.48.1985.

40. Menke A, Casagrande S, Geiss L, Cowie CC. Prevalence of and trends in diabetes among adults in the United States, 1988-2012. Jama. 2015;314(10): 1021-9. https://doi.org/10.1001/jama.2015.10029.

41. Mirouze J, Jaffiol C, Bernard C, Cartry E. The prediabetes of Klinefelter's syndrome. Diabete. 1966;14(2):57-9.

42. Wu FC, Tajar A, Beynon JM, et al. Identification of late-onset hypogonadism in middle-aged and elderly men. N Engl J Med. 2010;363(2):123-35. https:// doi.org/10.1056/NEJMoa0911101.

43. Wang $\mathrm{C}$, Jackson $\mathrm{G}$, Jones $\mathrm{TH}$, et al. Low testosterone associated with obesity and the metabolic syndrome contributes to sexual dysfunction and cardiovascular disease risk in men with type 2 diabetes. Diabetes Care. 2011; 34(7):1669-75. https://doi.org/10.2337/dc10-2339.

44. Corona G, Monami M, Rastrelli G, Aversa A, Tishova Y, Saad F, et al. Testosterone and metabolic syndrome: a meta-analysis study. J Sex Med. 2011;8(1):272-83. https://doi.org/10.1111/j.1743-6109.2010.01991.x.

45. Zitzmann $M$, Bongers $R$, Werler $S$, et al. Gene expression patterns in relation to the clinical phenotype in Klinefelter syndrome. J Clin Endocrinol Metab. 2015;100(3):E518-23.

46. Panimolle F, Tiberti C, Granato S, Semeraro A, Gianfrilli D, Anzuini A, et al. Screening of endocrine organ-specific humoral autoimmunity in $47, \mathrm{XXY}$
Klinefelter's syndrome reveals a significant increase in diabetes-specific immunoreactivity in comparison with healthy control men. Endocrine. 2016 52(1):157-64. https://doi.org/10.1007/s12020-015-0613-y.

47. Pei $D$, Sheu WH, Jeng CY, Liao WK, Fuh MM. Insulin resistance in patients with Klinefelter's syndrome and idiopathic gonadotropin deficiency. J Formos Med Assoc. 1998;97(8):534-40.

48. Lee KW, Cha CK, Uhm C, Kwon OY, Lee SK, Chung YS, et al. Impaired glucose tolerance associated with klinefalter syndrome. J Korean Soc Endocrinol. 1998;13:495-500.

49. Kapoor D, Goodwin E, Channer KS, Jones TH. Testosterone replacement therapy improves insulin resistance, glycaemic control, visceral adiposity and hypercholesterolaemia in hypogonadal men with type 2 diabetes. Eur J Endocrinol. 2006;154(6):899-906. https://doi.org/10.1530/eje.1.02166.

50. Tan WS, Low WY, Ng CJ, Tan WK, Tong SF, Ho C, et al. Efficacy and safety of long-acting intramuscular testosterone undecanoate in aging men: a randomised controlled study. BJU Int. 2013;111(7):1130-40. https://doi.org/1 $0.1111 /$ bju.12037

51. Gianatti EJ, Dupuis P, Hoermann R, et al. Effect of testosterone treatment on glucose metabolism in men with type 2 diabetes: a randomized controlled trial. Diabetes Care. 2014;37(8):2098-107. https://doi.org/10.2337/dc13-2845.

52. Grossmann M, Hoermann R, Wittert $G$, Yeap BB. Effects of testosterone treatment on glucose metabolism and symptoms in men with type 2 diabetes and the metabolic syndrome: a systematic review and metaanalysis of randomized controlled clinical trials. Clin Endocrinol (Oxf). 2015; 83(3):344-51.

53. Groth KA, Skakkebæk A, Høst C, Gravholt CH, Bojesen A. Clinical review: Klinefelter syndrome--a clinical update. J Clin Endocrinol Metab. 2013;98(1): 20-30. https://doi.org/10.1210/jc.2012-2382.

\section{Publisher's Note}

Springer Nature remains neutral with regard to jurisdictional claims in published maps and institutional affiliations.

Ready to submit your research? Choose BMC and benefit from:

- fast, convenient online submission

- thorough peer review by experienced researchers in your field

- rapid publication on acceptance

- support for research data, including large and complex data types

- gold Open Access which fosters wider collaboration and increased citations

- maximum visibility for your research: over $100 \mathrm{M}$ website views per year

At $\mathrm{BMC}$, research is always in progress.

Learn more biomedcentral.com/submissions 